\title{
Economic and Mathematic Modeling of Labour Efficiency
}

\author{
Marina V. Simonova ${ }^{1}$ \\ Haidar I. Galiullin²

\begin{abstract}
1 Samara State University of Economics, Russia, 443090, Samara, Sovetskoi Armii Street, 141 2 Nonprofit Organization «Centre for Development of Nuclear Innovation Cluster of Dimitrovgrad, Ulyanovsk Region» Correspondence: Samara State University of Economics, 443090, Russia, Samara, Sovetskoi Armii Street, 141

Email:m.simonova@mail.ru
\end{abstract}

\section{Doi:10.5901/mjss.2015.v6n6s3p527}

\section{Abstract}

The article is dedicated to the author's methodology of economic and mathematic modeling of labour efficiency indicators. Conditions and type of labour determine social and economic efficiency of labour, the increasing of which is becoming necessary for any organization. Economic and mathematic modeling makes it possible to calculate planned indicators of labour efficiency according to different parameters. The research suggests methods of building one-factor and multifactor statistic and dynamic economic and mathematical models of labour effectiveness indicators. The efficiency of labour of different categories of workers can be presented by two groups of indicators: indicators of production efficiency (labour efficiency) and indicators of economic (financial) efficiency (profitability of labour). On the basis of the analysis of the studied factors the dependence was derived which can be expressed in a deterministic or stochastic factor economic and mathematical model. Advantages of a stochastic model of efficiency of work consist is that incomplete, vague and insufficiently formalized information is also taken into account through a complex factorial function with variable structure and the changing nature of dynamics. The presented method allows a high degree of reliability in modeling planned increase in efficiency of labour. Thus, when evaluating and planning the efficiency of labour of the workers of commercial enterprises not only productivity but also profitability of labour should be taken into account.

Keywords: economic and mathematical modeling, economic and mathematical models, efficiency of labour, harmonic analysis, spectral analysis.

\section{Introduction}

In modern economic activities more and more attention is paid to the indicators of efficiency of these activities and different processes (Shlychkov V., Nestulaeva D. 2009). Efficiency is becoming the most succinct indicator of costs, profits and time of economic and technological processes by which you can evaluate the work of complete systems and individual processes and elements. Increasing of complexity of technologies, the increasing dynamics of social, political and economic systems, reducing of the periods of technological structures caused increasing demand for labor efficiency as the most important component of companies' work. Recent studies increasingly show that the most important element in increasing the efficiency of production is the quality of the workforce that can provide high efficiency of labor (Abdukarimov I., Ten N. 2011, Simonov M. 2012). The conditions and contents of work determine socio-economic efficiency of labor, the increase of which is becoming a necessary condition of the organizations' activities (Kotlyar B. 2014). There is a need for an accurate assessment of the impact of social factors on the efficiency of work, as decent work, social climate, the number of real-time employment and other factors have a significant impact on human activities at the workplace. At the same time, the high degree of uncertainty and unpredictability of many of the processes associated with work does not allow to calculate the required work results with the use of the known methods. Economicmathematical modeling allows calculating the planned indicators of labor efficiency on various parameters (Semenov K. 2014, Savchenko, I.A. 2008, Rusyak, Ketova, K. 2007). The modeling of the effectiveness of labour of the workers of industrial enterprises is of scientific interest, as it is necessary to establish a proved relationship of labor efficiency and profitability of products. The presented method allows modeling a planned increase in efficiency of labour with a high degree of reliability. 


\section{Methods of Modeling the Efficiency of Labour}

The efficiency of labour of different categories of workers can be represented by two groups of indicators: indicators of production efficiency (productivity of labour) and indicators of economic (financial) effectiveness (productivity of labour) (Galiullin H. 2012).

Recent studies suggest the methods of frontier research in the measurement of economic performance, such as Bayesian methods, self-tuning method, duality theory and the analysis of the sample of asymptotic properties (MurilloZamorano, L. 2004). Multifactor models of aggregate labour productivity are also used to analyze the effect of different factors in order to identify the reserves of growth and the increase of productivity (Semenov S., Komarova O., Permin S., Laricheva N. 2007, Diligenskiy N., Panormov V. 2007). The possibilities of simulation modeling of production situation development can be considered in general for large industrial enterprises and for individual parts of a complex object. For technological processes in some cases discrete-event approach is used which is more suitable for homogeneous objects (Radaev A., Leventsov V. 2011). The mathematical relationship of human capital, productivity and economic growth is considered by many scientists and the quality of workforce is increasingly used as the defining parameter (Kuznetsov Y. 2012). The use of economic and mathematical methods allows finding optimal variants which in their turn make it possible to reach significant increase of the indicators influencing the growth of the economic efficiency (Terezova G., Zyablikova O. 2013). But modeling of the increase of efficiency of labour with the use of economic and mathematical methods is practically not described in scientific literature because theoretical provisions of it are not studied enough and there are a lot of vague, unpredictably changing factors. However, with a certain abstraction labour efficiency can be expressed by determined or stochastic factor economic and mathematical model.

The determinate model of efficiency of work can be expressed by multiplicative or multiple economic model (Galiullin H., Ermakov G. 2013). Stochastic model of efficiency of work can be represented by a complex factor function with variable structure, changing nature of the dynamics, containing incomplete, vague and insufficiently formalized information.

Methods of modeling indicators of efficiency of labour in the form of determinate models are adequately developed and used for their planning and analysis.

The author's technique of modeling indicators of efficiency of labour in the form of stochastic models for their forecasting is presented in the journals earlier reviewed (Ermakov G., 2013).

In the management of efficiency of labour there was used the following methods of step- by-step building of economic and mathematical models of such efficiency.

At the first stage the analysis of the socio-economic structure of the workers and their performance is made, the results of which form the initial list of factors influencing these figures.

At the second stage single-factor static and dynamic economic and mathematical models of the efficiency of labour of the workers are constructed. Specification of the models is determined on the basis of visual assessment of the location of the points on the correlation field, the results of the previous studies and considerations of professional nature, based on the knowledge of the economic substance of the relationship between the efficiency of labour $(\mathrm{y})$ and the relevant factor (s). The experience of the author in the field of construction of single-factor static models of efficiency of work shows that, as a rule, we can only form the models of such types:

- linear regression: $y=a+b x+\varepsilon$;

- regressions nonlinear in the explanatory variables:

- polynomials of different degrees: $y=a+b_{1} x+b_{2} x^{2}+b_{3} x^{3}+\varepsilon$;

- equilateral hyperbole: $a+\frac{b}{x}+\varepsilon$;

- regression nonlinear in the parameters evaluated:

- degree regression: $\mathrm{y}=\mathrm{a} \mathrm{x}^{\mathrm{b}} \mathcal{E}$;

- exponential regression: $y=a b^{x} \varepsilon$.

Single-factor dynamic model of productivity may be presented in the form of trigonometric polynomial:

$$
\mathrm{y}(\mathrm{t})=\mathrm{A}_{0}+\mathrm{A}_{\mathrm{ot}}^{\prime}+\sum_{\mathrm{m}=1}^{\mathrm{n}} \mathrm{A}_{\mathrm{m}} \sin \left(\frac{2 \pi}{\mathrm{P}_{\mathrm{m}}} \mathrm{t}+\varphi_{\mathrm{m}}\right)
$$

where $\mathrm{A}_{0}+\mathrm{A}_{\mathrm{or}}$ is a trend in the form of linear function; $\mathrm{A}_{\mathrm{m}}$ is the amplitude of vibrations; $\mathrm{P}_{\mathrm{m}}$ is the period to be revealed; $\varphi_{\mathrm{m}}$ is harmonic phase.

The effectiveness of labor in dynamics may not contain any trend or cyclical fluctuations and each following level in 
the time series can be represented by the sum of the average level of the series and a random variable. In this situation, the behavior of the efficiency of labor can be adequately approximated by a set of simple dynamic models of the following type:

$$
\mathrm{y}(\mathrm{t})=\mathrm{f}\left(\mathrm{x}^{\mathrm{t}} ; \theta_{\mathrm{i}}\right) ; \mathrm{i}=\overline{1, \mathrm{n}}
$$

where $\mathrm{f}\left(\mathrm{x}^{\mathrm{t}-1} ; \theta_{\mathrm{i}}\right)$ is a piece- linear difference regression function representing the Markov model of the first type:

$$
\mathrm{f}\left(\mathrm{x}^{\mathrm{t}-1} ; \theta_{\mathrm{i}}\right)=\sum_{\mathrm{j}=1}^{\mathrm{m}} \phi\left(\mathrm{x}^{\mathrm{t}-1} ; \beta_{\mathrm{ij}}\right) \mathrm{y}\left(\mathrm{x}^{\mathrm{t}-1} ; \alpha_{\mathrm{ij}}\right) ; \mathrm{i}=\overline{1, \mathrm{n}} \text {, }
$$

where $\mathrm{y}^{\mathrm{y}\left(\mathrm{x}^{\mathrm{t}-1} ; \alpha_{\mathrm{ij}}\right)}$ is a linear regression determined only in the area ${ }^{\Theta}$ of the values of the argument; $\phi\left(\mathrm{x}^{\mathrm{t}-1} ; \beta_{\mathrm{ij}}\right)$ is a characteristic function $\Theta_{i j}$.

The effectiveness of labour can be expressed by the Markov model of the second type:

$$
\mathrm{y}(\mathrm{t})=\mathrm{f}\left(\mathrm{x}^{\mathrm{t}-1}, \mathrm{x}^{\mathrm{t}-2} ; \theta_{\mathrm{i}}\right) ; \mathrm{i}=\overline{1, \mathrm{n}}
$$

Of course, the real data on labor productivity may not fully represent one of any of the above models. In most cases they contain all three components. Each level of labor productivity is determined by the trend, seasonal variations and random variable. The econometric approach to the calculation of the efficiency of labor is represented by various scientists (Heshmati A., 2003). Different parametric and non-parametric approaches to measuring labour efficiency can have in the context static, dynamic and concrete forms of modeling.

The dynamic multifactor model of labour efficiency can be expressed by the following mixed economic and mathematical model:

$$
\mathrm{y}(\mathrm{t})=\mathrm{f}_{0}\left(\mathrm{x}_{\mathrm{i}}\right)+\mathrm{f}\left(\mathrm{x}_{\mathrm{i}}\right) \mathrm{t}+\sum_{\mathrm{m}=1}^{\mathrm{n}} \mathrm{f}_{\mathrm{k}}\left(\mathrm{x}_{\mathrm{i}}\right) \sin \left(\frac{2 \pi}{\mathrm{P}_{\mathrm{m}}} \mathrm{t}+\varphi_{\mathrm{m}}\right) \text {. }
$$

The method of building single-factor economic and mathematical dynamic models of labour efficiency consists of the following stages:

The first stage. Statistic single-factor and multifactor regression models of labour efficiency are formed.

The second stage. The analysis of the constructed models aimed at the revealing of periodical (seasonal) variations of labour efficiency within the limits of the trend month by month is made.

The third stage. The Time series of labour efficiency with the seasonal effect are studied by the method of harmonic analysis.

The fourth stage. The task of spectral analysis is formulated. On the given values of the function $Y_{k}$, (labour efficiency) in the moments

$$
\mathrm{t}_{\mathrm{k}}=\frac{\mathrm{K} * \mathrm{~T}}{\mathrm{~N}}, \quad \mathrm{~K}=\overline{0, \mathrm{~N}-1}
$$

We approximate $(\mathrm{t})$ on the interval $(0, \mathrm{~T})$ by the trigonometrical polynomial of the type:

$$
\mathrm{Y}(\mathrm{t})=\mathrm{A}_{0}+\mathrm{A}_{0 \mathrm{t}}^{\prime}+\sum_{\mathrm{m}=1}^{i} \mathrm{~A}_{\mathrm{m}} * \sin \left(\frac{2 \pi \mathrm{t}}{\mathrm{P}_{\mathrm{m}}}+\varphi_{\mathrm{m}}\right) \text {, }
$$

Spectral analysis allows revealing hidden periodicity, i.e. find the value $\mathrm{P}_{\mathrm{m}}$. The trigonometrical polynomial (7)is represented as an exponential function:

$$
\mathrm{Y}(\mathrm{t})=\sum_{\mathrm{m}=1}^{\mathrm{i}} \mathrm{C}_{\mathrm{m}} * \mathrm{e}^{\frac{2 \pi \mathrm{t}}{\mathrm{P}_{\mathrm{m}}}},
$$

Where coefficients $\mathrm{C}_{\mathrm{m}}$ are found by the inverse Fourier transformation formula which has the following form for the end discrete series:

$$
\mathrm{C}_{\mathrm{m}}=\frac{1}{\mathrm{~N}} \sum_{\mathrm{K}=0}^{\mathrm{N}-1} \mathrm{Y}_{\mathrm{k}} * \mathrm{e}^{-\mathrm{Y} \frac{2 \pi \mathrm{t}}{\mathrm{P}_{\mathrm{m}}}}
$$

The graph of dependence of variables $\left|C_{m}\right|^{2}$ from $m$ is called называется Fourier line spectrum where $P_{m}$ is the period aliquot to the length of implementation $T(1 \leq T \leq 120)$, $m$ is harmonic number.

The fifth stage. The parameters for the trigonometric function (7) are determined by the least square method:

$$
\sum_{\mathrm{K}=0}^{\mathrm{N}-1}\left[\mathrm{Y}\left(\mathrm{t}_{\mathrm{k}}\right)-\mathrm{Y}_{\mathrm{k}}\right]^{2} \text {, }
$$

The sixth stage. The series of observations, the values of which represent resulting interaction of certain 
components with periodic random error is formed:

$$
\left\{\begin{array}{l}
\mathrm{Y}_{\mathrm{k}}=\sum_{\mathrm{k}=1}^{\mathrm{i}} \mathrm{q}_{\mathrm{i}}\left(\mathrm{t}_{\mathrm{k}}\right)+\Pi_{\mathrm{k}}, \\
\mathrm{t}=\frac{\mathrm{K} * \mathrm{~T}}{\mathrm{~N}}, \mathrm{k}=\overline{0, \mathrm{~N}-1,} \\
\mathrm{Y}_{\mathrm{i}}(\mathrm{t})=\mathrm{A}_{\mathrm{i}} * \sin \left(\frac{2 \pi \mathrm{t}}{\mathrm{P}_{\mathrm{i}}}+\varphi_{\mathrm{i}}\right)
\end{array}\right\},
$$

where $\Pi_{\mathfrak{K}}$ is the value of random error. Such a series can be viewed as a discrete stationary time series that allows you to define the parameters of its harmonic components using methods of spectral analysis.

The seventh stage. The selective spectral density function or selective spectrum is studied. For the series (11):

$$
\mathrm{S}(\mathrm{f})=\mathrm{T} *\left|\mathrm{C}_{\mathrm{f}}\right|^{2} \text {, }
$$

where $C_{f}$ is Fourier transformation of the series (11):

$$
\mathrm{C}_{\mathrm{f}}=\sum_{\mathrm{K}=0}^{\mathrm{N}-1} \mathrm{Y}_{\mathrm{k}} * \mathrm{e}^{-\mathrm{j} 2 \pi t_{\mathrm{k}}} \text {, }
$$

The parameter $f$ is called frequency, the function $S(t)$ is determined on the continuous range of frequencies $0 \leq \mathrm{f} \leq\left(\frac{1}{2 \mathrm{H}}\right)$. $\mathrm{H}=\mathrm{T} / \mathrm{N}$ is a time step.

The selective range of time series (11) can be regarded as a superposition of the selective spectra of its periodic components qi $(\mathrm{t})$ and pure random process $\mathrm{P}(\mathrm{t})$.

If the process contains hidden periodicity and the frequency is $f=1 / P$ the function $S_{f}$ has maximum. $P$ corresponds to the period of harmonic component with maximum amplitude.

The eighth stage. The harmonic component is excluded from the series (11).

The ninth stage. This exclusion is repeated several times till the series become a pure random process (white noise). The successive exclusion of harmonic components allows avoiding the effect of imposition of frequencies.

The tenth stage. The borders of stably determined periods are calculated:

$$
2 \mathrm{H} \leq \mathrm{P} \leq \frac{\mathrm{NH}}{2} \text {, }
$$

As the Fourier transformation is symmetrical, the random spectrum is also a symmetrical function with regard to point

$f=0$. That is why it is enough to calculate $S(f)$ according to the formula (12) for $f \in[0,1 / 2 H]$. It is expedient to calculate the random function of spectral density with frequencies $f=\frac{\mathrm{m}}{\mathrm{NH}}, \mathrm{m}=0,1, \ldots, \frac{\mathrm{N}}{2}$, where $\mathrm{m}$ is the index of spectral function.

The function can be calculated with the help of quick Fourier transformation and then determine its maximum value. The formula (12) is:

$$
\mathrm{S}(\mathrm{f})=\mathrm{S}_{\mathrm{m}}=\frac{\mathrm{H}}{\mathrm{N}}\left|\sum_{\mathrm{K}=0}^{\mathrm{N}-1} \mathrm{Y}_{\mathrm{k}} * \mathrm{e}^{-\mathrm{j} 2 \pi \mathrm{mk} \mathrm{N}}\right|^{2} \text {, }
$$

The period of harmonic component having maximum amplitude $P=1 / f$. The series (11) is:

$$
\mathrm{Y}_{\mathrm{k}, \mathrm{r}}=\mathrm{A}_{\mathrm{r}} * \sin \left(\frac{2 \pi \mathrm{t}_{\mathrm{k}}}{\mathrm{P}_{\mathrm{r}}}+\varphi_{\mathrm{r}}\right), \mathrm{k}=0,1, \ldots, \mathrm{N}-1
$$

If $Y_{k, r}=Y_{k}$ the equation (16) is equivalent to the system of linear equation:

$$
\left(\begin{array}{l}
Y_{k}=\omega^{*} X_{k}+V^{*} Z_{k}, k=0,1, \ldots, N-1 ; \\
\omega=A * \cos \varphi ; \\
V=A * \sin \varphi ; \\
X_{k}=\sin \frac{2 \pi t_{k}}{P} ; \\
Z_{k}=\cos \frac{2 \pi t_{k}}{P} .
\end{array}\right),
$$

The eleventh stage. The system of equations is solved in relation to $\omega, V$ by the method of the least squares.

The twelfth stage. The values of $A$ and $\varphi$ are calculated. Now the parameters of harmonic component with 
maximum amplitude of the series (12) are completely determined.

The thirteenth stage. The errors of the model parameters are calculated according to the formulas:

$$
\begin{aligned}
& \sigma_{\mathrm{A}}^{2}=\frac{\sigma_{\omega}^{2} * \omega^{2}+\sigma_{\mathrm{V}}^{2} * \mathrm{~V}^{2}}{\omega^{2}+\mathrm{V}^{2}}, \\
& \sigma_{\varphi}^{2}=\frac{\sigma_{\omega}^{2} * \mathrm{~V}^{2}+\sigma_{\mathrm{V}}^{2} * \omega^{2}}{\left(\omega^{2}+\mathrm{V}^{2}\right)^{2}}, \\
& \Delta \mathrm{f}=\frac{1}{\pi \mathrm{NH}} \arcsin \frac{\sigma}{\mathrm{A}}, \\
& \Delta \mathrm{P}=\frac{\mathrm{P}^{2}}{\pi \mathrm{NH}} \arcsin \frac{\sigma}{\mathrm{A}},
\end{aligned}
$$

where $\sigma_{\mathrm{A}}^{2}, \sigma_{\varphi}^{2}$ is the dispersion of the parameters $\mathrm{A}$ and $\varphi ; \sigma$ - average square error of approximation (16); $\Delta \mathrm{f}, \Delta \mathrm{P}$ - errors in determination of frequency and period.

The fourteenth stage. Construction of the dynamic single-factor model of labour productivity.

The fifteenth stage. Checking the adequacy to the real conditions of the model according to F-criterion

Multifactor static and dynamic economic and mathematical models of labour efficiency are build. When making multifactor regression models of labour efficiency one should take into consideration that none of the factors influencing the resulting indicator can not be considered in isolation with the others. Changing of a factor may significantly influence the other factors. For example, changing of the age lead to the changing of such factors as professional experience and the level of education. Sufficiently accurate approximation of the static relationship of labor efficiency and its determinants is provided by multifactor equation of the second-degree polynomial in which the factors are given with integer exponents, and the coefficients - in the linear form:

$$
\mathrm{Y}=\mathrm{b}_{0}+\sum_{\mathrm{i}=1}^{\mathrm{n}} \mathrm{b}_{\mathrm{i}} \mathrm{X}_{\mathrm{i}}+\sum_{\mathrm{i}, \mathrm{j}}^{\mathrm{n}} \mathrm{b}_{\mathrm{ij}} \mathrm{X}_{\mathrm{i}} \mathrm{X}_{\mathrm{j}}+\sum_{\mathrm{i}=1}^{\mathrm{n}} \mathrm{b}_{\mathrm{ii}} \mathrm{X}_{\mathrm{i}}^{2},
$$
$1,2, \ldots, n)$.

where $b_{0}, b_{i}, b_{i i}, b_{i j}$ are estimations of the model coefficients; $n$ is the number of factors; $x_{i}, X_{j}$ are the factors, $(i, j=$

The selection is based on the analysis of static characteristics according to $t$ criterion of Student for linear multifactor models and the coefficient of determination for single-factor models.

To construct the model that meets the requirements of the dynamic multifactor model we study the Fourier coefficients (7) in conjunction with the factors analyzed. To do this, it is necessary to build, for example, the model of the form (7) according to the dynamic series for each worker.

Table 2. The dependence of Fourier coefficients on the factors

\begin{tabular}{|c|c|c|c|c|c|c|c|c|c|}
\hline \multirow{2}{*}{ № of the worker } & \multicolumn{5}{|c|}{ Furye coefficients } & \multicolumn{4}{|c|}{ Factors } \\
\cline { 2 - 11 } & $\mathrm{A}_{0}$ & $\mathrm{~A}_{0}^{\prime}$ & $\mathrm{A}_{1}$ & $\ldots$ & $\mathrm{A}_{\mathrm{m}}$ & $\mathrm{X}_{1}$ & $\mathrm{X}_{2}$ & $\ldots$ & $\mathrm{X}_{\mathrm{k}}$ \\
\hline 1 & $\mathrm{~A}_{10}$ & $\mathrm{~A}_{10}^{\prime}$ & $\mathrm{A}_{11}$ & $\ldots$ & $\mathrm{A}_{1 \mathrm{~m}}$ & $\mathrm{X}_{11}$ & $\mathrm{X}_{12}$ & $\ldots$ & $\mathrm{X}_{1 \mathrm{k}}$ \\
\hline$\ldots$ & $\ldots$ & $\ldots$ & $\ldots$ & $\ldots$ & $\ldots$ & $\ldots$ & $\ldots$ & $\ldots$ & $\ldots$ \\
\hline $\mathrm{i}$ & $\mathrm{A}_{\mathrm{i} 0}$ & $\mathrm{~A}_{\mathrm{i} 0}^{\prime}$ & $\mathrm{A}_{\mathrm{i} 1}$ & $\ldots$ & $\mathrm{A}_{\mathrm{im}}$ & $\mathrm{X}_{11}$ & $\mathrm{X}_{\mathrm{i}}$ & $\ldots$ & $\mathrm{X}_{\mathrm{ik}}$ \\
\hline$\ldots$ & $\ldots$ & $\ldots$ & $\ldots$ & $\ldots$ & $\ldots$ & $\ldots$ & $\ldots$ & $\ldots$ & $\ldots$ \\
\hline $\mathrm{n}$ & $\mathrm{A}_{\mathrm{n} 0}$ & $\mathrm{~A}_{\mathrm{n} 0}^{\prime}$ & $\mathrm{A}_{\mathrm{n} 1}$ & $\ldots$ & $\mathrm{A}_{\mathrm{nm}}$ & $\mathrm{X}_{\mathrm{n} 1}$ & $\mathrm{X}_{\mathrm{n} 2}$ & $\ldots$ & $\mathrm{X}_{\mathrm{nk}}$ \\
\hline
\end{tabular}

The analyzed factors $X_{1}, \ldots, X_{k}$ are relatively slightly change. As a result, the relationship between the coefficients of Fourier $A_{0}, A_{0}^{\prime}, A_{1}, \ldots, A_{m}$ and the factors $X_{1}, X_{2}, \ldots, X_{k}$ can be rather accurately approximated by linear dependence. Using the method of the least squares we build multifactor equations of regression:

$$
\begin{aligned}
& A_{0}=f_{0}\left(X_{1}, \ldots, X_{k}\right)=a_{00}+a_{10} X_{1}+\ldots+a_{k 0} X_{k}, \\
& A_{0}^{\prime}=f_{0}^{\prime}\left(X_{1}, \ldots, X_{k}\right)=a_{00}^{\prime}+a_{10}^{\prime} X_{1}+\ldots+a_{k 0}^{\prime} X_{k}, \\
& A_{1}=f_{1}\left(X_{1}, \ldots, X_{k}\right)=a_{01}+a_{11} X_{1}+\ldots+a_{k 1} X_{k},
\end{aligned}
$$




$$
A_{\mathrm{m}}=\mathrm{f}_{\mathrm{m}}\left(\mathrm{X}_{1}, \ldots, \mathrm{X}_{\mathrm{k}}\right)=\mathrm{a}_{0 \mathrm{~m}}+\mathrm{a}_{1 \mathrm{~m}} \mathrm{X}_{1}+\ldots+\mathrm{a}_{\mathrm{km}} \mathrm{X}_{\mathrm{k}} \text {, }
$$

The Fourier coefficients (7) are determined in the form of the linear function from the social factors $X_{1}, X_{2}, \ldots, X_{k}$. Introducing in the equation (7) the dependences (23), we form the following model:

$$
\mathrm{Y}(\mathrm{t})=\mathrm{f}_{0}\left(\mathrm{X}_{1}, \ldots, \mathrm{X}_{\mathrm{k}}\right)+\mathrm{f}_{1}\left(\mathrm{X}_{1}, \ldots, \mathrm{X}_{\mathrm{k}}\right) * \mathrm{t}+\sum_{\mathrm{i}=1}^{\mathrm{m}} \mathrm{f}_{\mathrm{k}}\left(\mathrm{X}_{1}, \ldots, \mathrm{X}_{\mathrm{k}}\right) * \sin \left(\frac{2 \pi \mathrm{t}}{\mathrm{P}_{\mathrm{i}}}+\varphi_{\mathrm{i}}\right)
$$

Such dependence will satisfy the requirements of identification of the dynamic model.

\section{The Results and Discussion: Economic and Mathematical Models of Labour Efficiency}

Realization of the method of economic and mathematical modeling of labour efficiency allows constructing the models of labour efficiency adequate to the real conditions.

For example, single-factor models of the productivity of labour of the workers from the main workshops of Dimitrovgrad enterprise producing carpets JSC "Covrotex" are presented in Table 3 (Sagan O., Ermakov G., 2007).

Table 3 presents the following factors: age $\left(x_{1}\right)$, working experience $\left(x_{2}\right)$, professional experience $\left(x_{3}\right)$, the level of education $\left(x_{4}\right)$, family status $\left(x_{5}\right)$, living conditions $\left(x_{6}\right)$, the duration of involuntary administrative leave $\left(x_{7}\right)$, the number of days of the delay of payment of wages $\left(x_{8}\right)$.

\begin{tabular}{|c|c|c|c|}
\hline The type of regression & Average mistake of approximation, \% & $\begin{array}{c}\text { Coefficient } \\
\text { (index) of determination }\end{array}$ & \begin{tabular}{|c|}
$\begin{array}{c}\text { F-criterion of } \\
\text { Fisher }\end{array}$ \\
\end{tabular} \\
\hline $\mathrm{y}_{\mathrm{x}_{2}}=95,7-0,0339 \mathrm{x}_{2}+0,0007 \mathrm{x}_{2}^{2}$ & 4,3 & 0,078 & 13,7 \\
\hline $\mathrm{y}_{\mathrm{x}_{3}}=95,6-0,0220^{\mathrm{x}_{3}}+0,0004^{\mathrm{x}_{3}^{2}}$ & 5,8 & 0,152 & 12,1 \\
\hline $\mathrm{y}_{\mathrm{x}_{4}}=95,7-0,6377^{\frac{1}{\mathrm{x}_{4}}}$ & 6,2 & 0,024 & 29,8 \\
\hline $\mathrm{Y}_{\mathrm{x}_{5}}=95,0^{\mathrm{X}_{5}^{-0,0038}}$ & 5,4 & 0,051 & 7,5 \\
\hline $\mathrm{y}_{\mathrm{x}_{6}}=95,0+0,0736 \mathrm{x}_{6}$ & 3,2 & 0,179 & 4,58 \\
\hline $\mathrm{y}_{\mathrm{x}_{7}=95,7-0,6377} \frac{1}{\mathrm{x}_{7}}$ & 6,8 & 0,716 & 883,9 \\
\hline $\mathrm{y}_{\mathrm{x}_{8}}=95,7-0,6377^{\frac{1}{\mathrm{x}_{\mathrm{s}}}}$ & 5,6 & 0,923 & 3948,9 \\
\hline
\end{tabular}

Table 3. Statistically significant models of the productivity of labour.

The data of Table 3 testify the adequacy of the labour efficiency models to the real conditions. The closest relationship is observed between the percentage of the production quotas and such factors as "the duration of the involuntary administrative leave" and "the number of days of the delay of payment of wages." It can be said that the differences in the efficiency of many companies are related to insufficient taking into account the factor of labor efficiency

(Chadwick C., Ahn J., Kwon K., 2012, Henderson, H. 2014).

On the results of the research the multifactor model of the productivity of labour was built:

$\mathrm{y}_{\mathrm{x}}=102,1+0,0072 \mathrm{x}_{1}-0,4659 \mathrm{x}_{2}+0,4172 \mathrm{x}_{3}-0,0632 \mathrm{x}_{4}-0,1842 \mathrm{x}_{5}+$

$+0,1053 x_{6}-0,1366 x_{7}-0,0002 x_{8}$.

The given equation shows that the percentage of the production quotas on average increased by 0,0072 and $0,4172 \%$ respectively at the 1 year increase of the age of the worker and her professional experience; decreased on average by $0,4659 \%$ at the 1 year increase of her total working experience; decreased by 0,0532 and $0,1842 \%$ at the increase of the level of education and family status by one point; increased by $0,1053 \%$ at the increase of the level of living conditions by one point; decreased by 0,1366 and $0,0002 \%$ at the increase of the duration of the involuntary administrative leave and the number of days of the delay of payment of wages by one day.

Non-linear multifactor mathematical models of labour efficiency: 
for circular knitting workshop of the enterprise №1:

$\mathrm{Y}=36,23+2,87 \mathrm{X}_{1}+2,97 \mathrm{X}_{2}+16,24 \mathrm{X}_{4}-0,002 \mathrm{X}_{1} \mathrm{X}_{2}+0,015 \mathrm{X}_{1} \mathrm{X}_{4}+$

$+0,048 \mathrm{X}_{2} \mathrm{X}_{4}-0,042 \mathrm{X}_{1}^{2}-0,086 \mathrm{X}_{2}^{2}-2,75 \mathrm{X}_{4}^{2}$

for knitting workshop of the enterprise №2:

$\mathrm{Y}=62,65+0,708 \mathrm{X}_{1}+5,17 \mathrm{X}_{2}+14,17 \mathrm{X}_{4}-0,113 \mathrm{X}_{1} \mathrm{X}_{2}+0,109 \mathrm{X}_{1} \mathrm{X}_{4}+$

$+0,112 \mathrm{X}_{2} \mathrm{X}_{4}+0,015 \mathrm{X}_{1}^{2}-0,0016 \mathrm{X}_{2}^{2}-1,77 \mathrm{X}_{4}^{2}$

for weaving workshop of the enterprise № 3 :

$\mathrm{Y}=97,93+2,64 \mathrm{X}_{2}-0,11 \mathrm{X}_{4}+1,52 \mathrm{X}_{5}-5,59 \mathrm{X}_{6}-0,03 \mathrm{X}_{2} \mathrm{X}_{4}+0,05 \mathrm{X}_{2} \mathrm{X}_{5}+$

$+0,25 \mathrm{X}_{2} \mathrm{X}_{6}-0,22 \mathrm{X}_{4} \mathrm{X}_{5}+0,61 \mathrm{X}_{4} \mathrm{X}_{6}-0,15 \mathrm{X}_{5} \mathrm{X}_{6}-0,10 \mathrm{X}_{2}^{2}$,

For knitting workshop of the enterprise № 4 :

$\mathrm{Y}=54,21+3,14 \mathrm{X}_{1}+2,49 \mathrm{X}_{2}-0,0018 \mathrm{X}_{1} \mathrm{X}_{2}+0,011 \mathrm{X}_{1} \mathrm{X}_{4}+0,16 \mathrm{X}_{2} \mathrm{X}_{4}-$

$-0,045 X_{1}^{2}-0,09 X_{2}^{2}$

where $X_{4}, X_{6}=\overline{1,5} ; X_{5}=\overline{1,4}$.

Checking of the models (26-29) according to $F$-criterion showed that the values of $F$-criterion: $F_{1}=47,65, F_{2}=$ $17,19, F_{3}=44,59, F_{4}=35,14$ are more than $\mathrm{F}_{\alpha}$ equal to 1,85, with при вероятности 0,95.

The average square deviation for the corresponding models: $\sigma_{1}=5,3 \%, \sigma_{2}=5,8 \%, \sigma_{3}=5,14 \%,{ }_{41}=6,14 \%$.

In order to determine the degree of influence of this or that factor on the efficiency of labour of the workers we calculated the coefficients of elasticity.

For the polynomial model of the second degree the coefficient can be determined by the following formula:

$\ni_{i}=\frac{\left(b_{i}+2 b_{i i} \bar{X}_{1}+\sum_{i, j}^{n} b_{i j} \bar{X}_{j}\right) \bar{X}_{1}}{\bar{Y}}$,

The coefficients of elasticity for the equations $26-29$ are presented in Table 4.

Table 4. Elasticity coefficients.

\begin{tabular}{|l|c|c|c|c|c|c|}
\hline \multirow{2}{*}{ Productivity of labour (№ of the model) } & \multicolumn{5}{|c|}{ Factors } \\
\cline { 2 - 7 } & $\mathrm{X}_{1}$ & $\mathrm{X}_{2}$ & $\mathrm{X}_{3}$ & $\mathrm{X}_{4}$ & $\mathrm{X}_{5}$ & $\mathrm{X}_{6}$ \\
\hline For the model 3.13 & 0,13 & 0,16 & - & 0,04 & - & - \\
(specific weight, \%) & 39,0 & 48,0 & - & 13,0 & - & - \\
\hline For the model 3.14 & 0,09 & 0,18 & - & 0,08 & - & - \\
(specific weight, \%) & 26,0 & 51,0 & - & 23,0 & - & - \\
\hline For the model 3.15 & - & $0,1966,0$ & - & 0,02 & 0,06 & $-0,0176,0$ \\
(specific weight, \%) & - & & - & 7,0 & 21,0 & - \\
\hline For the model 2.16 & 0,11 & 0,14 & - & 0,04 & - & - \\
(specific weight, \%) & 38,0 & 48,0 & - & 14,0 & - & - \\
\hline
\end{tabular}

By analyzing these equations we can find that changing of the average evaluation of the factor leads to the changing of the efficiency of labour of the workers. When the average fixed values are $X_{1}, X_{4}, X_{5}, X_{6}$, changing of professional experience of workers by 1 year leads to the changing of labour efficiency of the workers at the enterprises №№ 1, 2, 3, 4 respectively by 1,$1 ; 0,9 ; 1,2 ; 1,0 \%$. When the average fixed values are $X_{1}, X_{2}, X_{5}, X_{6}$ changing of the level of education by one point leads to changing of the labour efficiency respectively by 2,$1 ; 2,3 ; 3,6 ; 2,6 \%$.

Additional analysis allows making a conclusion that labour efficiency increases when professional experience increases up to 17 years, the level of education increases up to 3 points, the level of living conditions - up to 5 points, of the family status - up to 4 points and then decreases within the limits of $0,7-2,2 \%$. The maximum efficiency of labour was observed for the workers with professional experience of 14-16years, with secondary education, married, having children and living in their own flat.

As the result of realization of the algorithm (7-21) we built the dynamic single-factor model of the dependence of labour efficiency $Y(t)$ on the time factor $t$ :

$$
\begin{aligned}
& \mathrm{Y}(\mathrm{t})=105,85+0,03 \mathrm{t}+2,89 \sin \left(\frac{2 \pi \mathrm{t}}{4,0}+5,14\right)+2,43 \sin \left(\frac{2 \pi \mathrm{t}}{6,0}+6,02\right)+1,48 \sin \left(\frac{2 \pi \mathrm{t}}{12,0}+1,64\right)+ \\
& +1,36 \sin \left(\frac{2 \pi \mathrm{t}}{3,0}+4,29\right)
\end{aligned}
$$


where $t$ is changing within the limits - $31,5-91,5$; the first month of the year 1979 corresponds to $-31,5$, then $t$ changes with the step of the 1 month.

The fragment of the comparative results of the calculation of the level of productivity of the workers of the cloth factory named after Stepan Razin of "Ulianovsktextilprom" is given in Table 5.

Table 5. Factual and forecasted values of the level of the productivity of labour of the workers.

\begin{tabular}{|c|c|c|c|c|c|}
\hline Month & $\mathrm{Y}_{\mathrm{k}}$ & $\mathrm{Y}(\mathrm{t})$ & Month & $\mathrm{Y}_{\mathrm{k}}$ & $\mathrm{Y}(\mathrm{t})$ \\
\hline 1 & 101,3 & 103,8 & 26 & 106,3 & 105,8 \\
\hline$\ldots$ & $\ldots$ & $\ldots$ & $\ldots$ & $\ldots$ & $\ldots$ \\
\hline 12 & 104,1 & 103,8 & 37 & 105,7 & 105,1 \\
\hline$\ldots$ & $\ldots$ & $\ldots$ & $\ldots$ & $\ldots$ & $\ldots$ \\
\hline 25 & 104,9 & 104,7 & 50 & 108,2 & 106,8 \\
\hline
\end{tabular}

The analysis of the data of Table 5 revealed the critical points of the level of labour efficiency of the workers. For example, it significantly increases in February, June and October and decreases in April, July and August. The efficiency of labour changes with the established periodicity. In the first harmonic period is equal to 4 months, then the period is equal to 6,12 and 3 months respectively. It means that the labour efficiency is changed periodically and the period of fluctuations equal to 4 months is the most significant. The average square deviation of the forecasted values from the factual ones is $1.14 \%$.

The realization of the algorithm (23-24) allowed to build the economic and mathematical dynamic multifactor model of labour efficiency:

$$
\begin{aligned}
& \mathrm{Y}(\mathrm{t})=94,89-0,21 \mathrm{X}_{1}+4,53 \mathrm{X}_{5}+1,02 \mathrm{X}_{6}+\left(0,43-0,01 \mathrm{X}_{1}-0,04 \mathrm{X}_{5}+0,03 \mathrm{X}_{6}\right) \mathrm{t}+ \\
& +\left(5,67-0,06 \mathrm{X}_{1}-0,13 \mathrm{X}_{5}\right) * \sin \left(\frac{2 \pi \mathrm{t}}{4,0}+5,1\right)+\left(3,07-0,04 \mathrm{X}_{1}+0,13 \mathrm{X}_{5}\right) * \sin \left(\frac{2 \pi \mathrm{t}}{6,0}+4,2\right)+ \\
& +\left(2,74-0,04 \mathrm{X}_{1}+0,12 \mathrm{X}_{5}\right) * \sin \left(\frac{2 \pi \mathrm{t}}{12,0}+3,8\right)+\left(2,97-0,05 \mathrm{X}_{1}+0,27 \mathrm{X}_{5}+\right. \\
& \left.+0,13 \mathrm{X}_{6}\right) * \sin \left(\frac{2 \pi \mathrm{t}}{3,0}+0,2\right)
\end{aligned}
$$

where $t$ is time factor, month. The phases $\varphi_{1}=5,1 ; \varphi_{2}=4,2 ; \varphi_{3}=3,8 ; \varphi_{4}=0,2$ correspond to the periods $P_{1}=4,0$; $P_{2}=6,0 ; P_{3}=12,0 ; P 4=3,0$.

The model (32) is checked for adequacy according to $\mathrm{F}$ - criterion. The calculated value of $\mathrm{F}-$ criterion is equal to 85,7 and is higher than the value from the table. It testifies the adequacy of the model to the real conditions of production.

The random results of the calculation of the efficiency of labour are given in the Table 6 .

The analysis of the data of the Table 6 shows that the forecasted retrospective level of labour efficiency periodically fluctuates depending on various factors.

Table 6. Forecasted retrospective values of the productivity of labour of the workers.

\begin{tabular}{|c|c|c|c|c|c|c|c|}
\hline \multicolumn{7}{|c|}{ Initial data: $\mathrm{X}_{1}=19, \mathrm{X}_{5}=1, \mathrm{X}_{6}=1$} \\
\hline Month & $\mathrm{Y}(\mathrm{t})$ & Month & $\mathrm{Y}(\mathrm{t})$ & Month & $\mathrm{Y}(\mathrm{t})$ & Month & $\mathrm{Y}(\mathrm{t})$ \\
\hline 1 & 90,6 & 10 & 94,5 & 19 & 98,2 & 28 & 93,6 \\
\hline$\ldots$ & $\ldots$ & $\ldots$ & $\ldots$ & $\ldots$ & $\ldots$ & $\ldots$ & $\ldots$ \\
\hline 9 & 90,1 & 18 & 103,9 & 27 & 100,2 & 36 & 97,7 \\
\hline \multicolumn{7}{|c|}{ Initial data: $\mathrm{X}_{1}=19, \mathrm{X}_{5}=3, \mathrm{X}_{6}=3$} \\
\hline 1 & 99,4 & 10 & 103,3 & 19 & 107,3 & 28 & 102,3 \\
\hline$\ldots$ & $\ldots$ & $\ldots$ & $\ldots$ & $\ldots$ & $\ldots$ & $\ldots$ & $\ldots$ \\
\hline 9 & 99,2 & 18 & 115,7 & 27 & 110,1 & 36 & 107,4 \\
\hline \multicolumn{7}{|c|}{ Initial data: $\mathrm{X}_{1}=30, \mathrm{X}_{5}=3, \mathrm{X}_{6}=3$} \\
\hline 1 & 100,8 & 10 & 103,5 & 19 & 106,1 & 28 & 100,9 \\
\hline$\ldots$ & $\ldots$ & $\ldots$ & $\ldots$ & $\ldots$ & $\ldots$ & $\ldots$ & $\ldots$ \\
\hline 9 & 100,0 & 18 & 113,2 & 27 & 107,6 & 36 & 104,6 \\
\hline \multicolumn{7}{|c|}{ Initial data: $\mathrm{X}_{1}=37, \mathrm{X}_{5}=4, \mathrm{X}_{6}=4$} \\
\hline
\end{tabular}




\begin{tabular}{|c|c|c|c|c|c|c|c|}
\hline 9 & 106,4 & 18 & 118,1 & 27 & 112,1 & 36 & 108,6 \\
\hline \multicolumn{7}{|c|}{ Initial data: $X_{1}=22, X_{5}=2, X_{6}=3$} \\
\hline 1 & 94,1 & 10 & 98,0 & 19 & 101,8 & 28 & 97,4 \\
\hline$\ldots$ & $\ldots$ & $\ldots$ & $\ldots$ & $\ldots$ & $\ldots$ & $\ldots$ & $\ldots$ \\
\hline 9 & 93,9 & 18 & 109,4 & 27 & 104,4 & 36 & 102,4 \\
\hline \multicolumn{7}{|c|}{ Initial data: $X_{1}=45, X_{5}=4, X_{6}=4$} \\
\hline 1 & 108,4 & 10 & 109,6 & 19 & 110,1 & 28 & 104,6 \\
\hline$\ldots$ & $\ldots$ & $\ldots$ & $\ldots$ & $\ldots$ & $\ldots$ & $\ldots$ & $\ldots$ \\
\hline 9 & 106,9 & 18 & 116,2 & 27 & 110,4 & 36 & 106,6 \\
\hline \multicolumn{7}{|c|}{ Initial data: $X_{1}=34, X_{5}=4, X_{6}=4$} \\
\hline 1 & 107,1 & 10 & 109,3 & 19 & 111,3 & 28 & 105,9 \\
\hline$\ldots$ & $\ldots$ & $\ldots$ & $\ldots$ & $\ldots$ & $\ldots$ & $\ldots$ & $\ldots$ \\
\hline 9 & 106,2 & 18 & 118,7 & 27 & 112,8 & 36 & 109,4 \\
\hline
\end{tabular}

For example, it was revealed that the level of labour efficiency of the 19-year old woman living in a hostel is $85,3 \%$ $106,2 \%$ and it is $93,0 \%-114-117 \%$ for the woman of the same age living in her own flat and having a child.

To make comparative analysis of the different models of labour efficiency we built economic and mathematical models of labour efficiency and labour profitability of the workers of the first shift of the carpet production of JSC "Covrotex" working on tufting machines Pickering, England.

Economic and mathematical model of the labour efficiency:

$$
\begin{aligned}
& Y=88,1+0,952 X_{1}+0,103 X_{2-0,509+0,043} X_{4}+0,176 X_{5+0,228} X_{6-0,218} X_{1+} \\
& +0,038 X_{8-0,0124} X_{1}^{2}+0,0034 X_{2}^{2}+0,006 X_{3}^{2}+0,00046 X_{4+0,0268} X_{s-0,0156}^{2} X_{6-}^{2} \\
& -0,0015 X_{-0,00065}^{2} X_{8}^{2},
\end{aligned}
$$

Economic and mathematical model of profitability of labour:

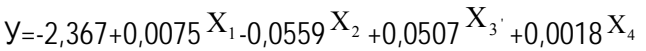

$$
\begin{aligned}
& -0,0006 X_{5}+0,0023 X_{6}+0,0079 X_{7}-0,0014 X_{8}
\end{aligned}
$$

The implementation of these models is presented by the data in Table 7.

Table 7. Comparative data on the productivity and profitability of the labour of the workers.

\begin{tabular}{|c|c|c|c|c|}
\hline \multirow{2}{*}{ № of the worker } & \multicolumn{5}{|c|}{ The efficiency of labour during the shift } \\
\cline { 2 - 5 } & Production standard, $\mathrm{M}^{2}$ & On productivity, $\mathrm{M}^{2}$ & The fulfillment of production standard, \% & On profitability, \% \\
\hline 3 & 475 & 474,7 & 99,9 & $-2,139$ \\
\hline 7 & 475 & 484,9 & 102,1 & $-2,189$ \\
\hline 14 & 475 & 489,6 & 103,1 & $-2,219$ \\
\hline 22 & 475 & 481,7 & 101,4 & $-2,150$ \\
\hline 31 & 475 & 495,6 & 104,3 & $-2,256$ \\
\hline 36 & 475 & 491,7 & 103,5 & $-2,222$ \\
\hline 42 & 475 & 482,3 & 101,5 & $-2,167$ \\
\hline Totally & $\mathrm{x}$ & 3400,5 & $\mathrm{X}$ & $\mathrm{X}$ \\
\hline Average value & 475 & 485,8 & 102,3 & $-2,192$ \\
\hline
\end{tabular}

The data of the Table 7 show that the workers work intensively but not profitably. More than that - the more intensive their work is the less is profitability.

\section{Conclusion}

So, to estimate and plan the efficiency of labour of workers it is necessary to take into account not only the indicators of productivity but also the indicators of profitability.

The suggested method of economic and mathematical modeling of labour efficiency allows determining the change of the level of labour efficiency in statics and dynamics depending on the changes in the state of the factors.

It was established that the indicators of labour efficiency can be evaluated as production effectiveness (productivity of labour) and economic (financial) effectiveness (profitability of labour). On the basis of the analysis of the studied factors the relationship was found which can be represented by determinate or stochastic factor economic and mathematical 
model. The advantage of the stochastic model of labour efficiency is that incomplete, vague and incompletely formalized information is taken into account via complex factor function with variable structure and changing character of dynamics.

There was presented the model of step-by-step constructing of economic and mathematical models of such efficiency. It was established that the efficiency of labour in dynamics may not contain any trend or cyclical fluctuations, and each following level in the time series can be represented by the sum of the average number and a random variable. The technique of construction of single-factor economic and mathematical dynamic models of efficiency of labour which consists of 12 stages, which allows you to build models adequate to the real conditions of efficiency of labour.

On the results of the study multifactor model of labor productivity is build which indicates that labor productivity varies periodically, and the period of variation equal to 4 month is the most significant. We calculated the coefficients of elasticity to determine the degree of influence of this or that factor on labor productivity. As a result of the algorithm realization the dynamic factor model of productivity $Y(t)$ dependence on the factor of time $t$ was built. Selected results of the calculation of labor productivity testify the adequacy of the model to real production conditions.

The data presented in the article show that the efficiency of labor is a more significant indicator for the efficiency of production than productivity because the more intensively the workers work, the less profitable is their work if the labour is inefficient. Therefore, to improve the profitability of production the focus should be made on the efficiency of work rather than on productivity. The proposed method makes it possible to model the efficiency of labor in the planned period. It seems perspective to continue the research on various parameters with changing external and internal data.

\section{References}

Chadwick, C., Ahn, J., \& Kwon, K. (2012, July 1). Human Resource Management's Effects on Firm-Level Relative Efficiency. Industrial Relations: A Journal of Economy and Society, 704-730-704-730.

Henderson, H. (2014, November 1). Considering Technical and Allocative Efficiency in the Inverse Farm Size-Productivity Relationship. Journal of Agricultural Economics.

Heshmati, A. (2003, February 1). Productivity Growth, Efficiency and Outsourcing in Manufacturing and Service Industries. Journal of Economic Surveys, 79-112-79-112.

Murillo-Zamorano, L. (2004, February 1). Economic Efficiency and Frontier Techniques. Journal of Economic Surveys, 33-77-33-77.

Abdukarimov I., Ten N. (2011, January 1). Management of Labour Efficiency in Business. Social and Economic Phenomena and Processes, 11-22.

Galiullin H., Ermakov G. (2013, January 1). Methodological Problems of Estimation of Economic Efficiency of Labour. Eurasian International Scientific Analytical Journal "The Problems of Modern Economy", 159-164.

Galiullin H. (2012, June 1). Methodological Approaches to the Estimation of Labour Efficiency at the Enterprises of Textile Industry. "The Problems of Modern Economy", 133-136.

Diligenskiy N., Panormov V. (2007, August 1). Synthesis and Identification of Mathematical Models of Production and Economic Systems. Bulletin of SSEU, 57-61.

Ermakov G. (2013, December 1). Criteria and Indicators of Efficiency. Scientific Bulletin of the Technological Institute - the branch of FGBOU VPO «Ulyanovsk State Academy of Agriculture named after P.A. Stolypin », 90-98.

Kotlyar B. (2014, January 1). The Efficiency of Labour and Social Efficiency. Non-ferrous Metals, 8-15.

Kuznetsov Y. (2012, January 1). Human Capital, Efficiency of Labour and Economic Growth. Economic Analysis: Theory and Practice, 2-17.

Radaev A., Leventsov V. (2011, March 1). Systems of Step-by-Step Imitation Modeling of Production Processes. Organizer of Production, 30-33.

Rusyak I., Ketova K. (2007, February 1). Economic and Mathematical Model of Analyzing and Forecasting of Human Capital. Economics, Statistics and Information Technologies. Bulletin of UMO, 56-61.

Savchenko I. (2008, January 1). The Practice of Research of the Relationship between Production Process and the Characteristics of Human Resources Potential with the Use of Economic and Mathematical Methods. Production Organizer, 46-51.

Sagan O., Ermakov G. (2007, April 1). The Improvement of the Management of Labour Efficiency with the Account of Social Factors. Bulletin of SSEU, 130-134-130-134.

Semenov K. (2014, March 1). Economic and Mathematical Modeling as The Function of Management (on the example of the regional enterprise of gas industry).Regional Economy: Theory and Practice, 46-61.

Semenov S., Komarova O., Permin S., Laricheva N. (2007, January 1). On the Development and Probation of Multifactor Model of Labour Efficiency. Economic Analysis: Theory and Practice, 36-40.

Simonova M. (2012, August 1). The Influence of Competitiveness and the Quality of Workforce on the Effectiveness of Work of an Organization.HR Manager.HR Management, 26-33.

Terezova G., Zyablikova O. (2013, January 1). Economic and Mathematical Modeling of the Optimization of Use of the Main Production Resources of Agricultural Organizations of Penza Region. Regional Economy: Theory and Practice, 43-48.

Shlychkov V., Nestulaeva D. (2009, January 1). Modern Concepts of the Estimation of the Effectiveness of an Industrial Enterprise Management. Bulletin of Kazan State Energy University, 41-50. 